
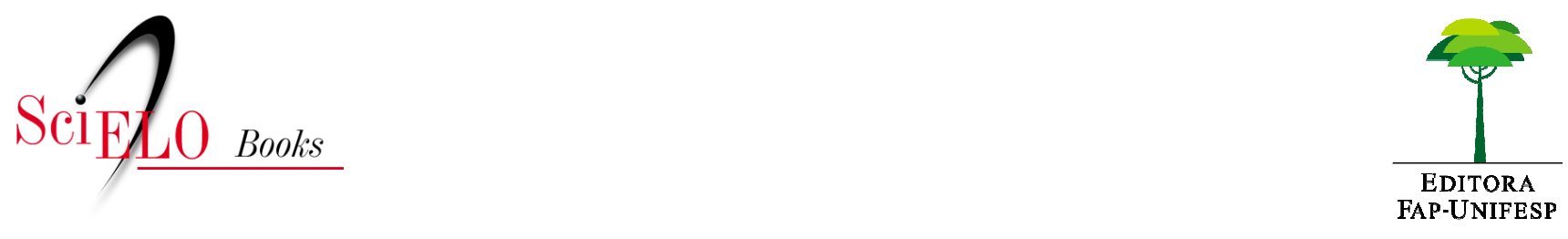

\title{
1 - Histórico da formação médica na Escola Paulista de Medicina e suas perspectivas na Universidade Federal de São Paulo
}

\author{
Durval Rosa Borges \\ Lucia de Oliveira Sampaio \\ Helena Bonciani Nader
}

\section{SciELO Books / SciELO Livros / SciELO Libros}

BORGES, DR., SAMPAIO, LO., and NADER, HB. Histórico da formação médica na Escola Paulista de Medicina e suas perspectivas na Universidade Federal de São Paulo. In PUCCINI, RF., SAMPAIO, LO., and BATISTA, NA., orgs. A formação médica na Unifesp: excelência e compromisso social [online]. São Paulo: Editora Unifesp, 2008. pp. 21-52. ISBN 978-85-61673-66-6. Available from SciELO Books <http://books.scielo.org $>$.

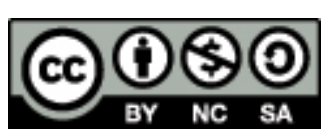

All the contents of this work, except where otherwise noted, is licensed under a Creative Commons Attribution-Non Commercial-ShareAlike 3.0 Unported.

Todo o conteúdo deste trabalho, exceto quando houver ressalva, é publicado sob a licença Creative Commons Atribuição Uso Não Comercial - Partilha nos Mesmos Termos 3.0 Não adaptada.

Todo el contenido de esta obra, excepto donde se indique lo contrario, está bajo licencia de la licencia Creative Commons Reconocimento-NoComercial-CompartirIgual 3.0 Unported. 


\section{I \\ A FORMAÇÃO MÉDICA NA UNIFESP \\ Contextualização Histórica, \\ Teórica e Metodológica}




\title{
Histórico da Formação Médica na Escola Paulista de Medicina e suas Perspectivas na Universidade Federal de São Paulo
}

\author{
Durval Rosa Borges, \\ Lucia de Oliveira Sampaio e Helena Bonciani Nader
}

INTRODUÇÃO

Os primeiros cursos de Medicina no Brasil foram criados por autorização de D. João vi, quando da vinda da família real portuguesa ao Brasil: o da Escola de Cirurgia da Bahia em fevereiro e o da Escola Anatômico-Cirúrgica e Médica do Rio de Janeiro em novembro, ambos em i 808. Apenas no final do século XIX seria criado o terceiro curso de Medicina, em Porto Alegre (I 898). Em 2006 o Brasil contava com I 49 cursos reconhecidos de Medicina, dos quais 29 no Estado de São Paulo.

A Escola Paulista de Medicina (EPM) foi fundada em I933, época que costuma ser associada ao nascimento da medicina moderna: "It is customary to place the date for the beginnings of modern medicine somewhere in the mid-I930s, with the entry of sulfonamides and penicillin into the pharmacopoeia and it is usual to ascribe to these events the force of a revolution in medical practice" (Lewis Thomas, 1979). 
O manifesto de fundação da EPM definia o duplo objetivo de criar uma escola médica e seu hospital-escola: "Uma escola médica exige instalaçóes hospitalares para o ensino das clínicas, e a criação de seu hospital não será menor serviço prestado a São Paulo pela nova Escola que, só por isso, faria jus ao maior carinho e ao melhor desvelo por parte da população paulista”. O que hoje parece óbvio não o era à época, tanto que o Hospital São Paulo, inaugurado em I940, foi o primeiro hospital-escola a ser especificamente construído no Brasil. A Faculdade de Medicina e Cirurgia de Sáo Paulo, criada em I9I3, desenvolveu a parte prática de seu curso na Santa Casa de São Paulo até 1945, quando a transferiu para o recém-inaugurado Hospital das Clínicas. A criação da EPM mudou o paradigma do ensino médico no país.

Ao ser instalada a EPM, em I933, os fundadores criaram também uma sociedade civil sem fins lucrativos, que recebeu o nome de Sociedade Cível Escola Paulista de Medicina, hoje conhecida como Associação Paulista para o Desenvolvimento da Medicina (sPDM). Ambas, EPM e SPDM trabalhando sempre voltadas para a finalidade precípua de servir ao ensino, à pesquisa e à assistência médica.

Neste capítulo relatamos parte de sua história: uma escola privada, criada por 33 jovens (3 I médicos e dois engenheiros) para o ensino profissional da Medicina, que se transformou em Universidade Federal de classe mundial. A evoluçáo do ensino de Medicina na instituição não foi linear durante seus quase 75 anos de existência; embora nem sempre os limites sejam precisos, pode ser analisada segundo quatro momentos de sua história: a implantação (I933-I950), a consolidação (I95 I-I97I), a institucionalização da pesquisa (I97I-I993), a transformação em universidade e a expansão (I 994-2006). É história peculiar, pois é sabido que When you've seen one medical school, you've seen one medical school.

- Implantação: é o período do regime de cátedra (I933-I950), que se inicia com a criação da EPM e do Hospital São Paulo (HSP, primeiro 
hospital-escola do país), e inclui a instalação do primeiro núcleo de pesquisa (Laboratório de Farmacologia e Bioquímica, no segundo andar do HSP em 1947). Ao ensino profissional associava-se a pesquisa.

- Consolidação: é o período do regime departamental (I95 I-I97I), que inicia com a criaçáo do primeiro departamento e inclui a federalização da EPM (I956), a criação do internato e do programa de residência médica (1957) e a posterior ampliação do internato para dois anos (I97I). Nesse período ocorreu a criação do curso de Ciências Biomédicas (I 966) destinado a formar profissionais envolvidos com o ensino e a pesquisa básica.

- Institucionalização da pesquisa (197I-I993): período no qual há progressivo credenciamento dos programas de pós-graduação stricto sensu. Consolida-se a iniciação científica, com crescente envolvimento de alunos de todos os cursos da instituição.

- Universidade e expansão: inicia-se com a transformação da ЕPM em universidade temática em 1994 (ciências da saúde) e alcança a expansão da Universidade Federal de São Paulo (Unifesp), que em cinco campi passa a ter dezenove cursos de graduação em três grandes áreas do conhecimento (biológicas, exatas e humanas), em 2007.

IMPLANTAÇÃO: O PERÍODO DA CÁTEDRA (I933-I950)

A escritura de Fundação e Organização da Escola Paulista de Medicina (I933), entidade privada, estabelecia que "É dever do sócio, quando fundador, realizar nos prazos estipulados a quota de capital, a que se houver obrigado no ato constitutivo da Sociedade". Ou seja: os estudantes pagavam para estudar e os professores pagavam para ensinar. Os primeiros "Estatutos da Escola Paulista de Medicina", 
aprovados apenas em I940 (ano de formatura da terceira turma de estudantes), deixavam ampla liberdade de ação aos catedráticos. Estes fatos foram determinantes para que o ensino de Medicina nas primeiras duas décadas de vida da EPM fosse a resultante da somatória de iniciativas independentes e individuais dos catedráticos, e não do desenvolvimento de um projeto pedagógico institucional. Mas já na origem ocorreu alguma integração entre áreas básica e clínica do ensino: o primeiro núcleo de pesquisa da EPM, o Laboratório de Farmacologia e Bioquímica, instalara-se no segundo andar do HSP, em I947. Em I95 I, o Laboratório passou a integrar o recém-organizado departamento de Clínica Médica, como parte do Serviço de Endocrinologia e Nutrição. Em 1956, o Laboratório de Farmacologia e Bioquímica instalou-se em edifício próprio, o hoje denominado Edifício José Leal Prado. O ensino ocorria em ambiente de pesquisa, que passa a influir na formação profissional.

O ensino de clínica médica iniciou-se em 1936 com a disciplina de Clínica Propedêutica Médica e completava-se com o da I $^{\underline{a}}$ Clínica Médica para a $5^{\underline{a}}$ série e da $2^{\underline{a}}$ Clínica Médica para a $6^{\underline{a}}$ série do curso. As primeiras aulas práticas de clínica médica realizaram-se no Hospital Humberto Primo (depois Matarazzo), onde doentes, previamente selecionados pelo corpo docente, ocupavam temporária e voluntariamente leitos em área especificamente cedida ao ensino da EPM, pela direção do hospital. Em junho de 1937 foi inaugurado, já no campus da rua Botucatu, o pavilhão Maria Theresa de Azevedo. Em seus dois andares abrigava sessenta leitos. No final de 1940, o HSP já possuía quatro andares em funcionamento, e o "Maria Theresa" destinou-se a atendimento ambulatorial. A figura I mostra o edifício sede da EPM, o Maria Theresa e o HSP. Quase tudo ocorria naquele quarteirão, limitado pelas ruas Botucatu (entrada da EPM), Pedro de Toledo, Napoleão de Barros (entrada do HSP) e Borges Lagoa.

A primeira turma de médicos da EPM formou-se em 1938 e o quadro I lista as disciplinas ensinadas em cada uma das seis séries naquele 


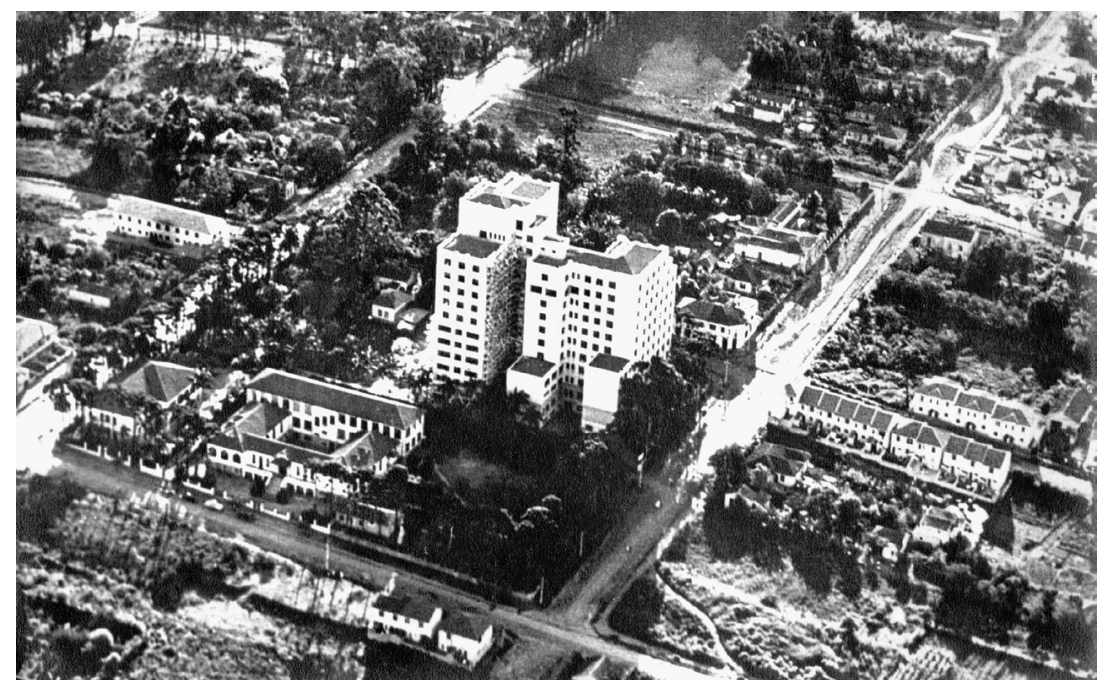

FIGURA I. Edifício sede da EPM e HSP, I948.

ano. Os quadros 2 e 3 detalham, para melhor compreensão, os conteúdos ministrados em uma cadeira básica (Química Fisiológica) e outra clínica (Clínica Médica). É respeitada a terminologia da época.

QUADRO I. Disciplinas do curso de Medicina da EPM, I 938

Série Matéria

I ${ }^{\underline{a}} \quad$ Anatomia; Física Biológica; Histologia, Embriologia Geral.

$2^{\text {a }} \quad$ Anatomia; Física Biológica; Fisiologia; Química Fisiológica.

$3^{\underline{a}} \quad$ Farmacologia; Microbiologia; Parasitologia; Patologia Geral.

$4^{\underline{a}} \quad$ Anatomia Patológica; Clínica Dermatológica; Clínica Propedêutica Cirúrgica; Clínica Propedêutica Médica; Técnica Cirúrgica.

$5^{\underline{a}} \quad$ Clínica de Moléstias Tropicais; Clínica Urológica; Higiene; Medicina Legal; Terapêutica Clínica; I 플 Clínica Médica.

$6^{\underline{a}} \quad$ Clínica Cirúrgica; Clínica Obstétrica; $2^{\underline{a}}$ Clínica Médica, Clínica Pediátrica Médica e Higiene Infantil, Ortopedia e Cirurgia Infantil. 
QUADRO 2. Química Fisiológica, I 938

\section{Parte Teórica}

I. Introdução. Definição e significação entre as outras ciências.

2. Leis da conservação da matéria e da energia. Ciclo da energia e matéria nos seres vivos. Síntese e aproveitamento da energia.

3. Composição dos seres vivos. Alimentos.

4. Alimentos inorgânicos. Água e sais.

5. Hidratos de carbono, Mono, di- e polissacarídios. Glucosídios.

6. Ésteres dos hidratos de carbono. Fermentação.

7. Gorduras. Ceras. Fosfatídios. Cerebrosídios. Esterinas. Carotenóides.

8. Proteínas. Caracteres gerais; (estado coloidal classificação).

9. Decomposição das proteínas. Ácidos aminados. Síntese de proteínas. Polipeptídios naturais e sintéticos. Dicetopiperazinas.

Io. Estrutura e tipos de ligação na molécula protéica.

I I. Proteínas simples e conjugadas; suas propriedades.

I 2. Nucleoprotides. Ácido nucléico e derivados. Bases nitrogenadas.

I 3. Catálise. Enzimas, seus caracteres gerais. Especificidade e reversibilidade da ação catalítica.

I 4. Sucos digestivos; sua composição e ação sobre os diferentes componentes dos alimentos.

I 5. Digestão. Absorção e assimilação. Fermentação; auto-intoxicação. Fezes.

I6. Sangue. Composição e caracteres de seus componentes. Coagulação. Hemólise.

I7. Hemoglobina e pigmentos conexos. Função respiratória do sangue.

I 8. Constantes físico-químicas do sangue. Dissociação iônica. Reação do sangue.

I9. Tampóes. Reservas alcalinas. Acidose e alcalose.

20. Linfa. Exsudato. Transudatos. Líquido cefalorraquidiano.

2 I. Metabolismo da água. Sua regulação e perturbações.

22. Metabolismo mineral. Absorção e eliminação das substâncias minerais. Modificações patológicas.

23. Metabolismo intermediário das proteínas. Suas perturbações patológicas.

24. Metabolismo intermediário dos hidratos de carbono. Papel da insulina. Diabetes. 
25. Metabolismo intermediário das gorduras. Corpos cetônicos. Modificações patológicas.

26. Oxidações e reduçóes nos tecidos.

27. Contração muscular.

28. Correlaçốes químicas. Hormônios.

29. Nutrição e crescimento.

30. Alimentos compostos. Deficiências alimentares.

31. Vitaminas e avitaminoses.

32. Urina. Caracteres gerais. Modificações patológicas.

\section{Parte Prática}

I. Acidimetria e alcalimetria. Iodimetria.

2. Determinação do pH colorimetricamente e pelo potenciômetro.

3. Pesquisa e dosagem dos hidratos de carbono.

4. Pesquisa e dosagem das gorduras.

5. Pesquisa e dosagem das proteínas e produtos do seu desdobramento.

6. Pesquisa sobre os componentes principiais da saliva e suco gástrico e de suas enzimas.

7. Idem do suco pancreático e da bile.

8. Determinação da reserva alcalina do sangue.

9. Determinação da taxa de glicose do sangue.

Io. Determinação do cálcio e fósforo do sangue.

I I. Determinação das proteínas do sangue.

I2. Determinação do $\mathrm{N}$ não protéico do sangue (característicos de seus derivados principais).

I 3. Determinação da hemoglobina do sangue (característicos de seus derivados principais).

I 4. Pesquisa dos principais componentes da urina normal e patológica.

I 5. Idem do líquido cefalorraquidiano.

I6. Pesquisa das substâncias principais do leite.

I7. Determinação colorimétrica dos carotenóides e da vitamina A. Reação de Carr-Price. 
I 8. Pesquisa da vitamina $\mathrm{C}$ na urina normal e patológicas; titulação do ácido ascórbico.

I9. Pesquisa e características principais das flavinas.

\section{QUadro 3. Programa de Clínica Médica, I 938}

I. Visita diária à enfermaria, sendo distribuídos os leitos pelos estudantes, com a obrigação das respectivas observações, conforme o modelo fornecido.

2. Exercícios de semiotécnica pelos assistentes, em turmas que não poderão exceder a dez estudantes.

3. Liçōes de clínica, tendo por objeto os casos que ocorrerem no serviço.

4. Uma vez por semana, aula sobre doentes de ambulatório, limitada à diagnose e terapêutica dos casos apresentados.

5. Conferência semanal destinada às generalizaçôes de doutrina sobre assunto prefixado.

6. Exercícios práticos à cabeceira dos doentes, pelos quais os estudantes serão distribuídos.

7. Cursos especiais durante o ano letivo ou no período de férias, para estudantes com a colaboração dos chefes de clínica e assistentes sobre determinados capítulos da patologia.

Em I950, o HSP tinha capacidade para trezentos leitos, dos quais I 80 na seção de indigentes e I 20 na de pensionistas; estes financiavam aqueles. No edifício-sede da EPM (ainda hoje sem nome) funcionavam cadeiras básicas pré-clínicas. Numa das alas do edifício achavam-se instaladas também a secretaria, a biblioteca e o anfiteatro que recebera o nome do ministro da Educação e Saúde Professor Raul Leitão da Cunha, cuja atuação fora importante para o credenciamento oficial do curso em I938. O ensino de algumas cadeiras era feito fora da sede da Escola. As aulas teóricas e práticas de Terapêutica Clínica eram dadas 
na Policlínica de São Paulo, à Rua do Carmo, onde também funcionava o Centro de Higiene Social anexo à cadeira de Dermatologia e Sifiligrafia. As aulas práticas de Clínica Ortopédica eram dadas no Pavilhão "Fernandinho Simonsen" da Santa Casa de Misericórdia. O curso de Clínica Psiquiátrica era ministrado no Serviço de Assistência aos Psicopatas e as aulas práticas de Medicina Legal no Pavilhão Médico-Legal. A Clínica Oftalmológica mantinha consultório e Centro de Estudos à Rua Condessa São Joaquim. No Hospital de Isolamento Emílio Ribas realizavam-se as aulas da Clínica de Moléstias Infecciosas.

Em I 950, realizou-se em São Paulo a primeira transmissão de televisão no Brasil. Em I95 I, foram criados o Conselho Nacional de Pesquisas e Desenvolvimento Tecnológico (CNPq), a Coordenaçáo de Aperfeiçoamento de Pessoal de Nível Superior (Capes), a Associação Médica Brasileira e realizou-se a I ${ }^{\underline{a}}$ Bienal de Artes Plásticas de São Paulo. Em I953, o Ministério da Educação e Saúde, criado em I937, se desmembra em Ministério da Saúde e Ministério de Educação e Cultura. Nesse mesmo ano, foi publicado o trabalho de J. D. Watson e F. H. C. Crick, "A Structure for Deoxyribose Nucleic Acid".

CONSOLIDAÇÃO: O PERÍODO DEPARTAMENTAL (I95 I-I97I)

Em i95 I, foi criado o Departamento de Clínica Médica. Fato ímpar, pois em instituição de caráter privado, e, como conseqüência da formulação de um projeto pedagógico, mudava-se "a regra do jogo universitário". Somente em I968, uma lei federal instituiria o sistema departamental na universidade brasileira. A proposta inicial de criação do Departamento vinha de 1949 e baseou-se na reformulação que Raul Leitão da Cunha (ministro da Educação e Saúde) fizera em diversos organismos do Ministério. A reformulação concedia autonomia à Universidade do Brasil (hoje Universidade Federal do Rio de Janeiro-UfrJ), modificando seu estatuto, e desenhava o modelo de 
constituição futura das universidades federais. O Estatuto da Universidade do Brasil (constituída inicialmente por seis institutos e catorze faculdades, dentre elas a Faculdade Nacional de Medicina) estabelecia em seu artigo 59 que "O regimento de cada uma das escolas e faculdades estabelecerá a organização didática e administrativa da mesma em departamentos, formados pelo agrupamento das cadeiras afins ou conexas". Na época, o diretor da EPM informou que, no Rio de Janeiro teve oportunidade de trocar idéias com o diretor do Departamento de Ensino Superior do Ministério, o qual aconselhou que a EPM estudasse muito bem o assunto em apreço, principalmente com referência ao futuro, pois "o que se pretendia era uma inovação no ensino médico, e traria conseqüências que deveriam ser bem ponderadas".

Em I956, decreto presidencial federalizou a EPM, mas não o HSP. O governo federal adquiriu o patrimônio da EPM e assumiu todos os seus compromissos, ao mesmo tempo que oficializou os professores catedráticos. O decreto ainda estabelecia que "para ensino das clínicas da Escola Paulista de Medicina, a entidade mantenedora do Hospital São Paulo assegurará a utilização de suas enfermarias gerais, instalaçôes e equipamentos, independente de qualquer indenização”.

Estes dois fatos (estrutura departamental e profissionalização do corpo docente) marcaram significativamente o ensino na EPM. No quadro 4, apresenta-se a relação de disciplinas ministradas em I963 em cada uma das seis séries, quando a estrutura departamental estendera-se para toda a EPM. Com trinta anos de existência a EPM substituíra o regime de cátedras pela estrutura departamental.

QUADro 4. Disciplinas do curso de Medicina da EPM em I 963

Série Matéria

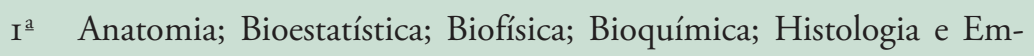
briologia Geral. 
$2^{\underline{a}} \quad$ Epidemiologia e Profilaxia Gerais; Farmacologia; Fisiologia; Microbiologia; Parasitologia; Patologia Geral.

$3^{\text {a }} \quad$ Anatomia Patológica; Clínica de Doenças Infecciosas e Parasitárias; Clínica Dermatológica; Clínica Médica; Clínica Otorrinolaringológica; Medicina Preventiva; Técnica Cirúrgica; Tisiologia.

$4^{\underline{a}} \quad$ Clínica Cirúrgica; Clínica Médica; Clínica Psiquiátrica.

$5^{\underline{a}} \quad$ Clínica Ginecológica; Clínica Neurológica; Clínica Oftalmológica; Clínica Ortopédica; Clínica Urológica; Medicina Legal; Terapêutica Clínica; Tisiologia.

6 $\quad$ Clínica Cirúrgica; Clínica Médica; Clínica Obstétrica; Clínica Pediátrica.

Detalhamos a seguir os conteúdos de uma disciplina básica (Bioquímica) e de uma disciplina clínica (Clínica Médica), em I963.

\section{Programa de Biofisica e Bioquímica em 1963}

Os cursos de Biofísica e Bioquímica eram desenvolvidos de maneira sincronizada de modo a permitir um máximo de entrosamento entre ambos. Essa conjugação de atividades estabelecia íntimo entrelaçamento dessas disciplinas, o que era uma motivação a mais para o aprendizado de ambas, e a melhor forma de apresentar, em um semestre, a matéria constante das duas disciplinas. O curso prático, parte fundamental do programa, era executado segundo um Guia Único do Curso Prático, especialmente preparado para esta finalidade.

\section{Biofísica}

Para o ano de 1963 o programa previa 42 horas de aulas teóricas sobre os temas: métodos óticos; termodinâmica; soluçôes; equilíbrio ácidobásico; estado coloidal; cinética da reação química; potenciais de óxido-redução; métodos biofísicos de estudo de metabolismo; raios $\mathrm{X}$ e radio-biologia. Cada um desses temas era ilustrado por 56 horas de aulas 
práticas. Após cada aula prática exigia-se dos estudantes um relatório sucinto da matéria apresentada, para julgar o aproveitamento individual.

\section{Bioquimica}

O curso teórico de 42 horas era dividido em 28 aulas, e versava sobre: hidratos de carbono; gorduras e esteróides; proteínas e ácidos nucléicos; enzimas, vitaminas e cadeia respiratória; digestão e valor nutritivo das proteínas; metabolismo intermediário; porfirinas e derivados. O curso prático de IO4 horas era dividido em quinze períodos de laboratório, com exercícios predominantemente individuais sobre: química analítica quantitativa, inclusive espectrofotometria; hidratos de carbono, gorduras e proteínas, inclusive cromatografia e eletroforese em papel; cinética de reaçóes enzimáticas; hemoglobina; oxidações biológicas inclusive respiração tissular; prova de carga com vitamina C e prova de tolerância à glicose no homem.

\section{Programa de Clínica Médica em 1963}

O programa de Clínica Médica incluía o clerckship (noviciado) e seguia-se, coerentemente, com o Internato e a Residência. Desenvolviase sob direção única (chefe do departamento) e em quatro séries consecutivas ( $3^{\underline{a}}, 4^{\underline{a}}, 5^{\underline{a}}$ e $6^{\underline{a}}$ séries).

$$
3^{\underline{a}} \text { série }
$$

O ensino visava apenas a Semiótica física e funcional e desenvolvia-se durante todo o ano letivo. Além da semiótica geral, médica e cirúrgica, era ensinada parte da semiótica neurológica, pediátrica e oftalmológica, como preparo para desenvolvimento do clerckship (noviciado).

$$
4^{\underline{a}} \text { série }
$$

Representava a base fundamental do ensino da Clínica Médica: o clerckship. O ideal seria haver número de leitos suficiente para toda 
turma, o que, infelizmente, não ocorria. Assim, a turma era dividida em duas. Enquanto a turma A fazia o "noviciado" no primeiro semestre, a turma B fazia estágio em Cardiologia, Pulmonologia, Nutrição, Nefrologia e Pediatria. No segundo semestre os estágios eram alternados, ou seja, a turma B fazia o "noviciado" e a turma A as especialidades referidas.

O noviciado era feito em enfermaria geral, que recebia doentes das especialidades, médicas e cirúrgicas. $\mathrm{O}$ trabalho nesta enfermaria era supervisionado pelos professores de Clínica Médica e de Clínica Cirúrgica (chefes dos respectivos departamentos) e era de responsabilidade direta de dois chefes de clínica: um médico e um cirurgião.

No decorrer do estágio os leitos eram divididos entre os estudantes ( 38 leitos para trinta estudantes) sendo a distribuiçáo feita pela ordem de entrada. Cabia ao estudante, no decorrer do "noviciado", a responsabilidade direta pelo doente. A supervisão era feita pelo residente (RI) e pelos médicos de tempo parcial que faziam plantôes no período da manhã e no período da tarde.

A turma que estagiava nas especialidades dispunha de leitos e de laboratórios, cujo trabalho variava de acordo com a especialidade. Assim, no estágio de Cardiologia, além da responsabilidade pela assistência supervisionada do doente, ainda realizava recapitulação da semiótica, aprendia a interpretação de eletrocardiogramas e exames radioscópicos e radiográficos. No estágio de doenças pulmonares havia revisão da semiótica física, aprendizado da realização das provas funcionais e interpretação de radiografias. No estágio de Nutrição e Nefrologia, além da assistência ao doente, o estudante era obrigado ao aprendizado das provas funcionais mais importantes.

O estágio em Pediatria era realizado na enfermaria juntamente com os estudantes internos da $6^{\underline{a}}$ série e com os RI e estagiários.

No decorrer da 4 a série, além do estágio - do tipo "noviciado" e nas especialidades -, o estudante participava das seguintes atividades: 
- Simpósios realizados às segundas-feiras juntamente com a $5^{\underline{a}}$ série.

- Às terças e sextas-feiras, visita à enfermaria geral realizada pelo professor de clínica.

- Reunião anatomoclínica às quartas feiras.

- Reunião geral às quintas-feiras para discussão dos casos clínicos internados na enfermarias.

- Reunião conjunta de clínica e cirurgia da secção de tórax (coração/pulmão) às sextas-feiras.

- Aula teórica aos sábados.

O conjunto destas atividades em Clínica Médica (estágio, reuniôes, aulas teóricas e simpósios) totalizava carga horária de oitocentas horas por aluno.

$$
5^{\underline{a}} \text { série }
$$

O estudante fazia estágios em Endocrinologia, Hematologia e Gastroenterologia. Estes estágios eram feitos nas enfermarias e particularmente nos ambulatórios. Às segundas-feiras havia simpósio para a $4^{\mathrm{a}} \mathrm{e}$ $5^{\underline{a}}$ séries conjuntamente. Às segundas, quartas e sextas-feiras havia ambulatório geral para metade da turma, alternando-se com Clínica Cirúrgica. Neste ambulatório dava-se grande responsabilidade ao estudante, pois o assistente realizava o controle da ficha de observaçáo somente após o estudante ter examinado o paciente. O Ambulatório Geral funcionava em inteira conexão com as cátedras de Terapêutica e de Medicina Preventiva. Com esta última a conexão era muito estreita através das visitas domiciliares. Computando todas as atividades, cada estudante da $5^{\underline{a}}$ série tinha um total de 264 horas de trabalho na Clínica Médica.

\section{$\sigma^{a}$ série}

O estudante fazia o Internato, assim registrado em documento da época:

I. A instituição do regime curricular de internato, pela EPM, representa uma das etapas de uma série de alteraçóes, realizadas desde 
há alguns anos e que resultaram na criação de um sistema de estágios que cremos permitirá ao acadêmico uma maior exposição aos importantes e freqüentes problemas que se destacam na atividade profissional do médico.

2. Em I 962 o programa da $6^{\underline{a}}$ série médica constituirá fundamentalmente de estágios em alguns dos setores clínicos. Este sistema de trabalho preenche os requisitos que o classificam de internato e terá um caráter de rodízio pelos seguintes departamentos ou serviços: Obstetrícia, Pediatria, Clínica Médica, Clínica Cirúrgica, Doenças Infecciosas (Hospital Emílio Ribas), Medicina Preventiva e Pronto Socorro do Hospital Municipal.

3. O estabelecimento deste tipo de internato como parte compulsória do Curso Médico qualifica o recém-formado a inscrever-se para admissão em 1963, no regime de residência da EPM e HSP.

4. Os candidatos aprovados no internato e admitidos em 1963 para o programa de residência ficam dispensados do rodízio a que se submeteram os graduados dos anos anteriores e passaráo a freqüentar seletivamente as disciplinas que constituem o ciclo cirúrgico (Obstetrícia e disciplinas afins; Cirurgia e especialidades) e o ciclo clínico (Clínica Médica, especialidades e disciplinas afins; Pediatria).

5. As bases fundamentais do programa serão elaboradas e aprovadas pelo Conselho Técnico-Administrativo da EPM e supervisionados por uma comissão constituída pelos diretores da EPM e do HSP e pelos catedráticos, ou seus representantes, das disciplinas que integram o rodízio do sexto ano.

6. A Comissão de Internato e Residência submeterá à aprovação do Conselho Técnico-Administrativo da EPM ou conjuntamente indicarão um assistente que exercerá as funçóes de coordenador do programa. Este elemento (coordenador) terá como funçâo principal a de trazer ao conhecimento da Comissão e/ou ao Conselho problemas a serem analisados e considerados. Ao coordenador 
cabe ainda responsabilizar-se pela execução e observância das normas estabelecidas.

7. O Internato funcionará ininterruptamente de 15 de janeiro a I 5 de dezembro. Neste período estão incluídas as épocas correspondentes aos exames de aprovação.

8. A Comissão responsável manterá um prontuário de cada residente, onde serão anotados e arquivados os relatórios enviados obrigatoriamente pelos serviços que integram o programa.

9. Não serão admitidos para os trabalhos do ano seguinte os elementos não classificados pela Comissão. Somente em condições excepcionais, poderá permitir-se a repetição do mesmo estágio, no seguinte ano. Esta exceção só será aplicável em apenas uma única oportunidade para cada candidato.

Io. Terminado o programa de residência, o estagiário receberá diploma oficial, assinado pelo diretor da EPM e do HSP, podendo também ao finalizar cada período de doze meses, solicitar o certificado correspondente ao tempo de atividade.

Em I97I, o Internato passou a ser de dois anos ( $5^{\underline{a}}$ e $6^{\underline{a}}$ séries do curso).

A EPM foi uma das primeiras a implantar (1957) programas de Residência Médica no Brasil, criados seguindo a mesma concepção dos programas desenvolvidos no começo do século xx nos Estados Unidos. Na década de I960, a Residência Médica na EPM/HSP era composta de dois ciclos básicos: o clínico e o cirúrgico, no qual se distribuíam os seus vinte médicos, dez clínicos e dez cirurgióes. As especialidades iniciavam-se no terceiro ano. Nas décadas seguintes, a Residência Médica passou a ser diversificada até que, em 2006, 64 programas diferentes são oferecidos para 555 médicos residentes. A mudança ocorrida a partir de 2003 no exame de seleção à Residência Médica (provas teórica, teórico-prática e prática) vem refletindo beneficamente no Internato. 
Em I 966 foi criado o curso biomédico. José Leal Prado, no último parágrafo do documento denominado "Sobre o Curso de Graduação, Mestrado e Doutoramento em Ciências Biomédicas da Escola Paulista de Medicina” registra:

Uma instituição como a Escola Paulista de Medicina sente-se limitada dentro da estrutura de um instituto isolado de ensino superior. A criação do curso de ciências biomédicas tornará mais amplo seu campo de atividade cultural e mais importante sua contribuição social. Se tivermos êxito nesta iniciativa, estaremos armazenando uma experiência valiosa ao mesmo tempo em que teremos maiores possibilidades para fazer uma segunda tentativa no caminho da Universidade Federal. Somente o futuro ditará a melhor conduta a seguir.

INSTITUCIONALIZAÇÃO DA PESQUISA CIENTÍFICA (I97 I-I993)

O ambiente de pesquisa estabelecido na década de 1960 propiciou em I970 o início de programas de pós-graduação na EPM, formalmente reconhecidos pela Capes. Esses programas passaram a ser alvo de um número expressivo de graduandos interessados em seguir carreira acadêmica. Vale notar que esses programas já apresentavam características multidisciplinares, envolvendo várias disciplinas e departamentos em projetos integrados de pesquisa. A EPM passa a ser reconhecida como centro de excelência na produção de conhecimento e na formação de mestres e doutores.

A diversidade de projetos de pesquisa, a potencialidade e a alta titulação do corpo docente levaram a Instituição a repensar o currículo dos cursos de graduação. Em I970, após ampla discussão, tem início, para os estudantes de Medicina, o curso de Ciências Fisiológicas, que engloba os conteúdos das antigas disciplinas de Físico-Química, Bioquímica, Biofísica, Farmacologia e Fisiologia, numa unidade curricular única. 
Como descrito por seus idealizadores, o curso foi criado "numa tentativa de melhorar o rendimento do corpo docente e discente", tendo "por objetivo promover nos alunos":

- O desenvolvimento da capacidade de observaçáo dos fatos experimentais e sua correta interpretação.

- O desenvolvimento da capacidade crítica, de tal modo que o aluno vá aprendendo o respeito à verdade e à objetividade científicas e que, ao estudar determinado assunto, seja capaz de abstrair o essencial dos fatos e os princípios estudados.

- O treinamento da capacidade de trabalho em equipe a fim de alcançar maior rendimento próprio e dos demais companheiros, tendo em vista o caráter eminentemente social da Medicina.

- O aprendizado e a compreensão dos temas do curso de Ciências Fisiológicas, organizado de tal maneira, que o aluno tenha uma visão global da matéria, possibilitando um aprofundamento posterior e a utilização na clínica dos conceitos aprendidos.

O curso era ministrado na $\mathrm{I}^{\underline{\underline{a}}}$ e $2^{\underline{\underline{a}}}$ séries. Os estudantes desenvolviam intensa atividade prática, nas quais os conteúdos das diferentes disciplinas eram abordados de forma conjunta e ilustrados em protocolos experimentais diretamente voltados à prática médica. Por exemplo, para o estudo da secreção gástrica, os estudantes realizavam procedimentos cirúrgicos que levavam a fístula gástrica em animais de experimentação. A discussão da atividade prática, acompanhada da leitura de livros-texto e trabalhos científicos relacionados aos temas, levavam à sedimentação dos conceitos teóricos. A elaboração de relatório era fundamental para a avaliação do aprendizado.

Em 1972, o governo federal implanta nas universidades o chamado Ciclo Básico Integrado. A EPM é obrigada a aderir a esse programa, e assim, o curso de Ciências Fisiológicas é descontinuado no seu segundo ano de existência. O Ciclo Básico Integrado agrupava todas as disciplinas básicas (Ciências Morfológicas: Anatomia, Histologia, 
Genética, Embriologia; e Ciências Fisiológicas: Físico-Química, Biofísica, Bioquímica, Fisiologia) que passaram a ser ministradas em conjunto aos ingressantes de todos os cursos da instituição: Medicina, Biomedicina, Enfermagem, Fonoaudiologia e Ortóptica.

O curso foi imposto à comunidade acadêmica sem a devida discussão e o resultado foi desastroso. Houve frustração por parte do corpo docente, que estava profundamente envolvido e comprometido com o projeto de ensino anterior. E ainda, diferenças importantes na vocação e necessidades de cada curso, na motivação e no conhecimento prévio dos estudantes, contribuíram para o fracasso do Ciclo Básico Integrado. Já em I973, foi subdividido em dois grupos, um voltado aos estudantes de Medicina e Biomedicina, e outro para os estudantes dos outros cursos. A partir de 1977, as disciplinas de Bioquímica, Biofísica, Fisiologia e Físico-Química passaram a ser ministradas separadamente para os estudantes de Medicina e Biomedicina. No início da década de I980, ocorre o mesmo para as disciplinas da área de Ciências Morfológicas.

No final da década de 1970 e durante os anos de I980, o currículo do Curso Médico da ЕРм passa a incluir conteúdos de novas áreas como Psicofarmacologia (I979) e, de forma pioneira, a Biologia Molecular (I985); na seqüência, Ciências Humanas (sociologia e psicologia médica em I986) e Informática Médica (I988), esta última não como disciplina isolada, mas integrada a unidades curriculares.

A iniciação científica (IC) consolidou-se na Unifesp a partir de I 992 com o Programa Institucional de Iniciação Científica (Pibic) do CNPq. Os responsáveis pela distribuição das bolsas entenderam ser papel de programa de iniciação científica transmitir ao aluno noções do método científico preparando-o para aprendizado com visão crítica. Alguns pressupostos têm sido considerados:

- Que o estudante esteja integrado em grupo com linha de pesquisa consolidada e produtiva pois a iniciação é do aluno e não de "orientador” não capacitado ou não envolvido com pesquisa científica. 
- Que a participação do aluno seja adequada à etapa de iniciação científica, não limitada à pesquisa bibliográfica ou à procura de pastas em arquivos. Esta participação deve ser ativa (obtenção de resultados próprios) e não passiva.

Iniciação científica é programa de caça a talentos (futuros pesquisadores), mas é fundamentalmente instrumento de melhor formação profissional. Questionário aplicado aos formandos do Curso Médico de 2006 revelou que os estudantes estão fortemente engajados em atividades acadêmicas extracurriculares. A figura 2, ao fim deste capítulo, mostra que ao terminarem a graduação, mais de $80 \%$ dos formandos participaram de programas de iniciação científica (IC com bolsas de CNPq ou Fapesp) ou de outros programas acadêmicos. Alguns dos indicadores da produção científica dos estudantes encontram-se no quadro 5. O número de bolsas de iniciação científica do CNPq (Pibic) concedidas a estudantes de Medicina no período entre I992 e 2006 está registrado no quadro 6. Anualmente, um entre quatro matriculados no curso de Medicina é bolsista do Pibic e ao final de seis anos de curso aproximadamente mais de $80 \%$ participou ativamente das atividades de pesquisa da instituição ( $85 \%$ dos formandos em 2006).

QUADRo 5. Produçáo acadêmica dos estudantes de Medicina que participaram ou não de programas de iniciação científica [Ic] na Unifesp

\begin{tabular}{lcc} 
& \multicolumn{2}{c}{ Média/Estudante $^{*}$} \\
Participação em eventos científicos & IC & Não IC \\
Resumos publicados em anais de congressos & 2,86 & 0,94 \\
Artigos completos publicados em periódicos & I,4I & 0,44 \\
& 0,36 & 0,06
\end{tabular}

*Dados obtidos através de questionário aplicado a todos os estudantes de Medicina formados em 2006. 
QUADRO 6. Número de estudantes matriculados e de bolsistas do Programa de Iniciação Científica Institucional do CNPq [Pibic] do Curso Médico da Unifesp [período 1992-2006]

\section{Númerolano}

Ano

1992

I993

I 994

I 995

1996

I997

1998

I999

2000

2001

2002

2003

2004

2005

2006

Total [ I 5 anos]
Estudantes matriculados

643

638

653

$66 \mathrm{I}$

669

$68 \mathrm{I}$

672

675

673

670

670

676

670

645

699

9995
Bolsas Pibic

84

I I 6

I74

I93

I9 I

I69

I 86

I 63

163

I62

I 45

I 4 I

I 53

I 62

I 55

2357

A consolidação da Iniciação Científica possibilitou que em 1998 fosse criado o programa MD-PhD na Unifesp, uma iniciativa inovadora que busca a integração entre a pós-graduação e a graduação na área médica com o objetivo de estimular a formação do pesquisador clínico. Através deste programa, estudantes de Medicina que participam ativamente de projetos de Iniciação Científica há pelo menos um ano, orientados por pesquisador credenciado em programa de pósgraduação de conceito cinco ou superior na Capes, poderão, uma vez 
selecionados por comissão especialmente criada para esse fim, iniciar seu doutorado antes da conclusão do curso.

\section{UNIVERSIDADE E A EXPANSÃO}

O PERÍODO DO CURRÍCULO NUCLEAR (I994-2006)

Em I 994 a EPM foi transformada em universidade temática da área da saúde, e passou a ser denominada Universidade Federal de São Paulo (Unifesp). Essa nova situação da instituição criou um ambiente propício a discussóes de novas idéias e perspectivas. Nesse período, iniciam-se os estudos para uma nova reforma do ensino de Medicina. A última mudança significativa havia ocorrido quando o Internato, que era de um ano, passou a ser desenvolvido nos dois últimos anos do curso ( $5^{\underline{a}}$ e $6^{\underline{a}}$ séries). A reforma foi balizada por características próprias da instituição e características gerais.

\section{Características da Unifesp}

- Todos docentes são titulados (pós-graduação stricto sensu) e, em sua maioria, trabalham em regime de tempo integral.

- Recebe estudantes da elite estudantil do país.

- Há integração científica e geográfica entre áreas básicas e profissionais, que não se separaram, como ocorreu nas demais universidades brasileiras por ocasião da reforma universitária.

- Há significativo envolvimento de estudantes em programas de iniciação científica, monitoria e extensão.

\section{Características gerais}

- Rápido e significativo progresso das ciências biomédicas, e conseqüente desenvolvimento de complexas técnicas diagnósticas e terapêuticas. O aumento excessivo de horas-aula (dentro da armadura dos seis anos de curso) não evitou que a educação médica 
perdesse o passo, de um lado, com os avanços da ciência biomédica e, do outro, com as necessidades da prática clínica.

- Desenvolvimento de novas concepçóes pedagógicas.

- Efetiva e ampla disponibilidade de acesso eletrônico a fontes de informaçáo biomédica.

A inclusão de novos conhecimentos em grade horária já congestionada só foi viável com a implantação do Currículo Nuclear, compreendido como o conhecimento essencial a ser adquirido por todo graduado em Medicina. Os módulos eletivos e o "tempo pró-aluno" (tempo de estudo, de pensar ou de lazer) completam o currículo pleno. A criação de espaços para a implantação das eletivas e do tempo pró-aluno exigiu integração interdisciplinar, tanto horizontal (básicobásicas e clínico-clínicas) como vertical (básico-clínicas). A integração fez com que a estrutura curricular fosse simultaneamente condensada e melhorada. O Currículo Nuclear foi implantado na Unifesp em I 997 e completou seu primeiro ciclo em 2002. Aspecto fundamental da reforma curricular foi o desenvolvimento de sistemática de avaliação, coerente com a mudança realizada. Têm sido avaliados o processo ensino/aprendizado (o estudante), os recursos humanos (corpo docente) e materiais da instituição. Quatro parâmetros vêm sendo utilizados para avaliação do ensino de Medicina na Unifesp: I. desempenho do estudante durante o curso, 2. desempenho do graduado na prova de seleção à Residência Médica e 3. a Prova do Progresso (Borges \& Stella, I999) e, mais recentemente, a prova de Avaliação de Habilidades e Atitudes, implantada em 2006.

$\mathrm{Na}$ figura 3 encontra-se a carga horária do curso de Medicina da Unifesp de 1938 a 2006, a porcentagem de evasão e a distribuição dos ingressantes por sexo, nesse mesmo período. Fica evidente que a carga horária atingiu o máximo admissível para seis anos de curso de graduação. Os dados mostram que a taxa de evasão reduziu-se significativamente a partir da metade da década de I950, que coincide 
com a federalização da instituição e sua presença no cenário nacional. Chama atenção a inclusão da mulher entre os ingressantes no Curso Médico, que passou de 0\% em 1933 para cerca de 50\% a partir dos anos de 1980 .

Em 2006 tem início o processo de expansão da instituição. Em 2007, a Unifesp deixou de ser universidade temática. No quadro 7 são apresentados os cursos e os respectivos anos de criação.

\begin{tabular}{|c|c|c|}
\hline Campus & Curso & Início \\
\hline \multirow[t]{5}{*}{ São Paulo } & Medicina & 1933 \\
\hline & Enfermagem & 1939 \\
\hline & Ortóptica/Tecnologia Oftálmica & $1962 / 1997$ \\
\hline & Ciências Biomédicas & I966 \\
\hline & Fonoaudiologia & 1968 \\
\hline \multirow[t]{5}{*}{ Baixada Santista } & Educação Física & 2006 \\
\hline & Fisioterapia & 2006 \\
\hline & Terapia Ocupacional & 2006 \\
\hline & Nutrição & 2006 \\
\hline & Psicologia & 2006 \\
\hline \multirow[t]{4}{*}{ Diadema } & Ciências Biológicas & 2007 \\
\hline & Engenharia Química & 2007 \\
\hline & Farmácia e Bioquímica & 2007 \\
\hline & Química & 2007 \\
\hline \multirow[t]{4}{*}{ Guarulhos } & Ciências Sociais & 2007 \\
\hline & Filosofia & 2007 \\
\hline & História & 2007 \\
\hline & Pedagogia & 2007 \\
\hline São José dos Campos & Ciência da Computação & 2007 \\
\hline
\end{tabular}


Os principais momentos da trajetória da Unifesp, que ilustram como emergiram e se estabeleceram as vocaçóes da Instituição, estão sumariados no quadro 8.

QUADRO 8. Principais momentos da trajetória da Unifesp

I933 Fundação

I936 Hospital São Paulo

I947 Primeiro núcleo de pesquisa

I95 I Primeiro departamento

I956 Federalização
Trinta e um médicos e dois engenheiros, movidos por criatividade, muito entusiasmo e determinação, fundaram a Escola Paulista de Medicina (EPM) e a Sociedade Paulista para o Desenvolvimento da Medicina (sPDM).

Com o objetivo de prover local adequado para a prática profissional dos estudantes, foi criado o primeiro hospital-escola do país.

Laboratório de Farmacologia e Bioquímica instala-se no segundo andar do HSP. Em I 956 o laboratório instalou-se em edifício próprio, hoje denominado Edifício José Leal Prado, construído e equipado para desenvolver pesquisa na área das químicas fisiológicas.

Encerra-se o período das cátedras com a criação do Departamento de Clínica Médica.

A EPM, até então de natureza privada, torna-se instituição pública e gratuita, transformando-se em estabelecimento isolado de ensino superior de natureza autárquica, vinculada ao Ministério de Educação. 


\begin{tabular}{|c|c|c|}
\hline 1957 & Residência Médica & $\begin{array}{l}\text { O avanço da Medicina levou à criação } \\
\text { de programa especial para adequar a } \\
\text { formação profissional às necessidades } \\
\text { da sociedade. A Residência Médica da } \\
\text { EPM foi a terceira do país. }\end{array}$ \\
\hline 1963 & $\begin{array}{l}\text { Expansão dos } \\
\text { laboratórios de pesquisa }\end{array}$ & $\begin{array}{l}\text { O crescimento e diversificação dos } \\
\text { grupos de pesquisa experimental leva- } \\
\text { ram à construção do Edifício Ciências } \\
\text { Biomédicas (hoje Edifício Antonio C. } \\
\text { M. Paiva), destinado exclusivamente a } \\
\text { abrigar novos laboratórios de pesquisa. }\end{array}$ \\
\hline 1965 & $\begin{array}{l}\text { Programa de saúde } \\
\text { indígena no Xingu }\end{array}$ & $\begin{array}{l}\text { Estudantes e docentes passam a atuar } \\
\text { no Parque Nacional do Xingu rea- } \\
\text { lizando ações de assistência médica, } \\
\text { imunização e educação em saúde, além } \\
\text { de pesquisa. }\end{array}$ \\
\hline I967 & $\begin{array}{l}\text { Biblioteca Regional } \\
\text { de Medicina }\end{array}$ & $\begin{array}{l}\text { O acervo da Biblioteca Central, cria- } \\
\text { da na EPM em } 1967 \text {, cresce, e através } \\
\text { de convênio com a Organização Pan- } \\
\text { Americana de Saúde passa a represen- } \\
\text { tar a Biblioteca Regional de Medicina } \\
\text { (Bireme). }\end{array}$ \\
\hline I970 & $\begin{array}{l}\text { Criação dos } \\
\text { primeiros programas } \\
\text { de pós-graduação }\end{array}$ & $\begin{array}{l}\text { A diversidade de projetos de pesquisa, } \\
\text { a potencialidade e a alta titulação do } \\
\text { corpo docente levaram a instituição a } \\
\text { criar, os primeiros programas de pós- } \\
\text { graduação na área da Saúde no Brasil. }\end{array}$ \\
\hline 1970 & $\begin{array}{l}\text { Programa assistencial } \\
\text { do Embu }\end{array}$ & $\begin{array}{l}\text { A instituição passa a atuar em unida- } \\
\text { des básicas no Município do Embu, } \\
\text { realizando atividades de assistência, } \\
\text { ensino e pesquisa. }\end{array}$ \\
\hline
\end{tabular}


I984 Infar

I992 Programa Institucional de Iniciação Científica (Pibic)

I994 Universidade Federal de São Paulo (Unifesp)

I996 Currículo Nuclear e Avaliação

I997 Expansão dos laboratórios de pesquisa ( $2^{\underline{a}}$ fase)
O crescimento da pesquisa e da pósgraduação levou à instalação de um novo edifício para abrigar as áreas de Biofísica, Bioquímica e Farmacologia. Instala-se o Instituto de Farmacologia e Biologia Molecular (Infar).

A forte vocação da Instituição em pesquisa e o expressivo número de orientadores credenciados nos programas de pós-graduação, vários dos quais atuando com estudantes bolsistas de Fapesp e CNPq, determinou a concessão de 108 bolsas no programa Pibic (8\% dos graduandos).

A Escola Paulista de Medicina, já consolidada e exercendo plenamente suas atividades nas áreas de ensino, pesquisa e extensão, foi reconhecida como universidade especializada na área da Saúde, passando a chamar-se Universidade Federal de São Paulo.

Reestruturação do curso de Medicina. Instituição da Prova do Progresso.

O final dos anos de 1990 representou uma segunda fase de expansão dos laboratórios de pesquisa na Unifesp com a inauguração de novos prédios específicos para investigação científica: Edifício de Pesquisa I e Edifício de Pesquisa II (2007), ocupados por mérito e equipes multiusuários. 
I998 Programa

$\mathrm{MD} / \mathrm{PhD}$

I998/ Parceria com a

I999 Rede de Saúde do

Estado e Município

I999 Fada

2000 Professor afiliado modalidade pesquisa

2002 Promed

2003 Expansão da Unifesp

2005 Pró-Saúde

2006 Professor afiliado modalidade ensino e avaliação
Integração entre a pós-graduação e a graduação na área médica.

A necessidade da prática dos graduandos no Sistema de Saúde fez com que a instituição firmasse convênios específicos em cenários adequados. Estudantes de graduação passam a desenvolver atividades no Centro de Saúde de Vila Mariana e UBSs de Sacomá/Ipiranga, atuando sob supervisão de docentes da Unifesp em atividades práticas.

Criação do Fundo de Apoio ao Docente e ao Aluno (Fada) para financiamento de projetos de pesquisa e participação em congressos no país e no exterior. A análise é feita por um comitê gestor externo e interno à instituição.

O Conselho Universitário (Consu) cria a categoria de professor afiliado (modalidade pesquisa).

Aprovação do projeto Promed do Curso Médico.

Em 2003 inicia-se a fase de expansão da Unifesp (quadro 5).

Aprovados os projetos Pró-Saúde dos cursos de Medicina e de Enfermagem da instituição.

O Conselho Universitário (Consu) cria a categoria de professor afiliado (modalidade ensino). Implantação da prova de Habilidades e Atitudes no Internato. 
Este rápido apanhado da história do ensino de medicina na Unifesp mostrou como seu projeto pedagógico foi se modificando com o contínuo progresso das ciências biomédicas e as mudanças sociais que ocorreram no país. A uma primeira fase caracterizada por dissociação entre o ensino das "cadeiras básicas" e as "cadeiras clínicas", seguiu-se fase de significativo avanço das ciências biomédicas com impacto direto na prática médica, bem como da fragmentação das disciplinas clínicas em especialidades e subespecialidades. Alguns desafios precisam agora ser equacionados, o principal talvez seja responder à questão: a estrutura departamental esgotou-se? Sua implantaçáo foi um avanço na substituição do regime de cátedras, mas a excessiva fragmentação dos departamentos e destes em disciplinas entrou em descompasso com o conhecimento atual biomédico. Como exemplo, podemos lembrar a endoscopia terapêutica cada vez mais resolutiva e a cirurgia minimamente invasiva convergindo para formação de novo médico/especialista. Outro exemplo é a síndrome metabólica que claramente não respeita a atual divisão dos departamentos e suas disciplinas.

Sabemos que é difícil aprender medicina, dada sua amplitude: medicina não é uma ciência biológica, mas sólida base de conhecimentos biomédicos é indispensável para seu pleno exercício; a medicina não é ciência exata, mas diagnóstico e tratamento devem basear-se em evidências demonstráveis; a medicina não é ciência humana, mas sem relação médico-paciente plena de compreensão e confiança não existe medicina. Sabemos ser difícil equilibrar, nas doses certas, ciência e arte na formulação do futuro médico; ou no dizer de Drummond "infundir ritmo ao puro desengonço".

Pensamos que vale terminar este capítulo com as palavras do poeta Guilherme de Almeida, na cerimônia do lançamento da estaca fundamental do HSP em I936: "Aí está, germinada e pros- 
perada a semente; aí está, florescido o ideal; aí está, frutificado o empreendimento! Aí está a Escola Paulista de Medicina. A árvore boa, em boa hora, sob um bom signo, numa boa terra e por boas mãos plantada”.

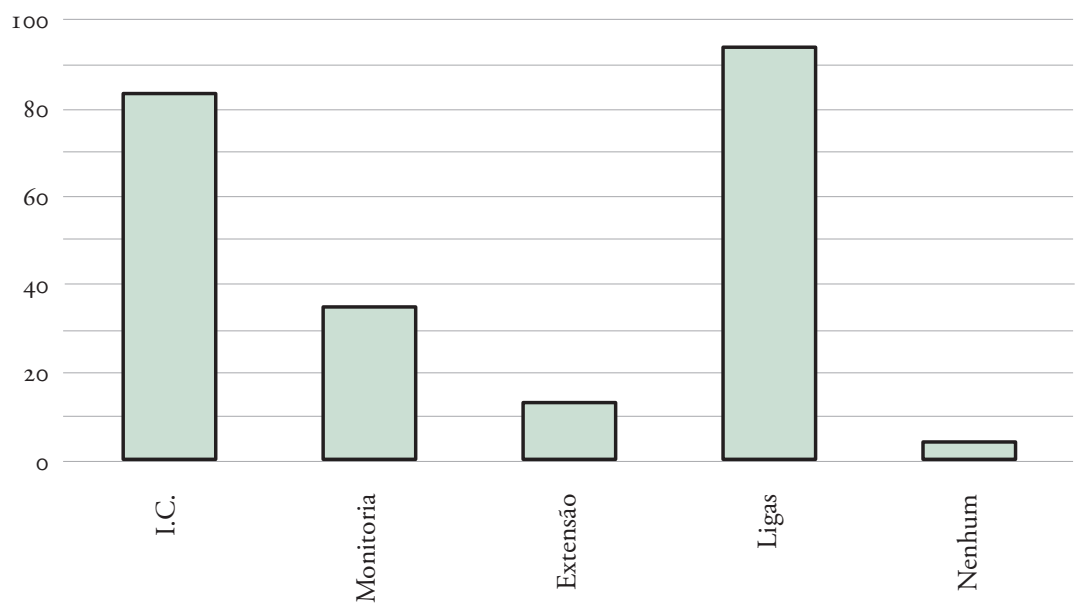

Figura 2. Porcentagem dos estudantes do Curso Médico formados em 2006 que aderiram a programas acadêmicos da Unifesp. 


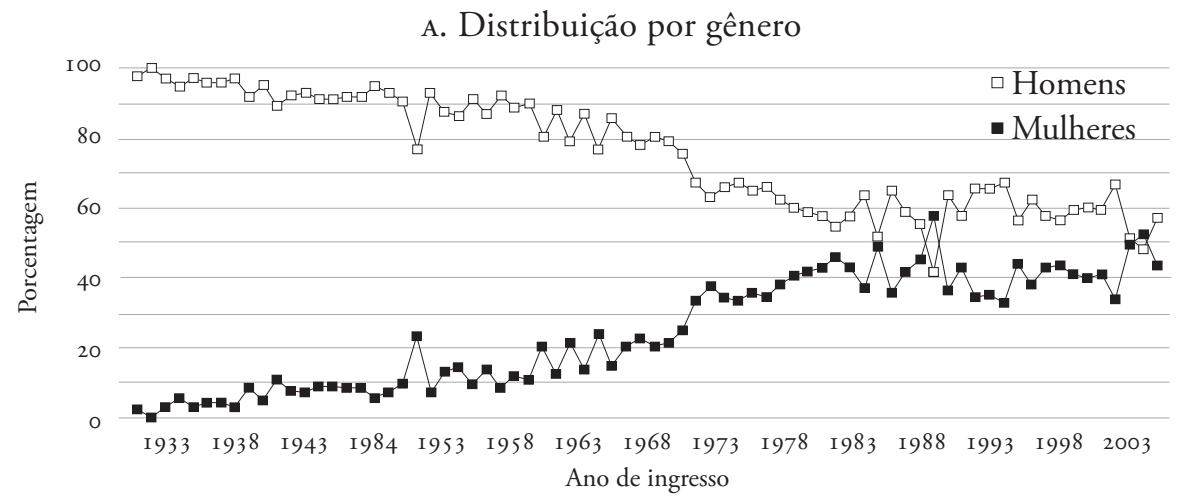

в. Porcentagem de evasão

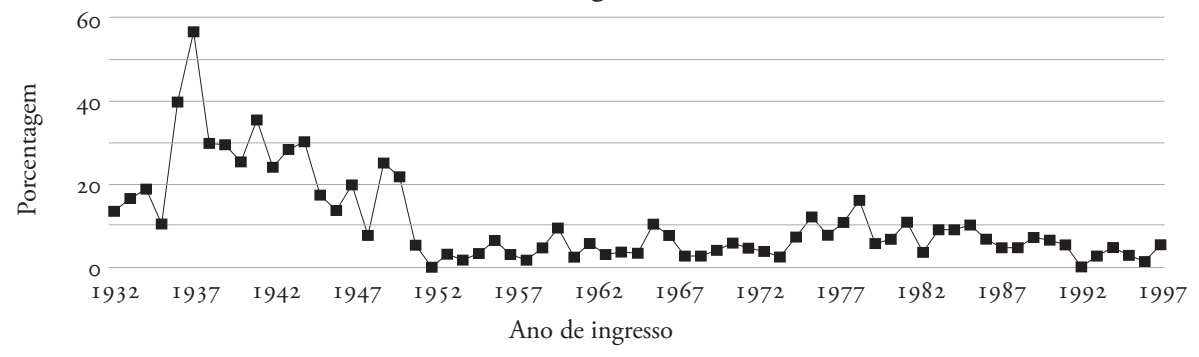

c. Carga horária total do curso

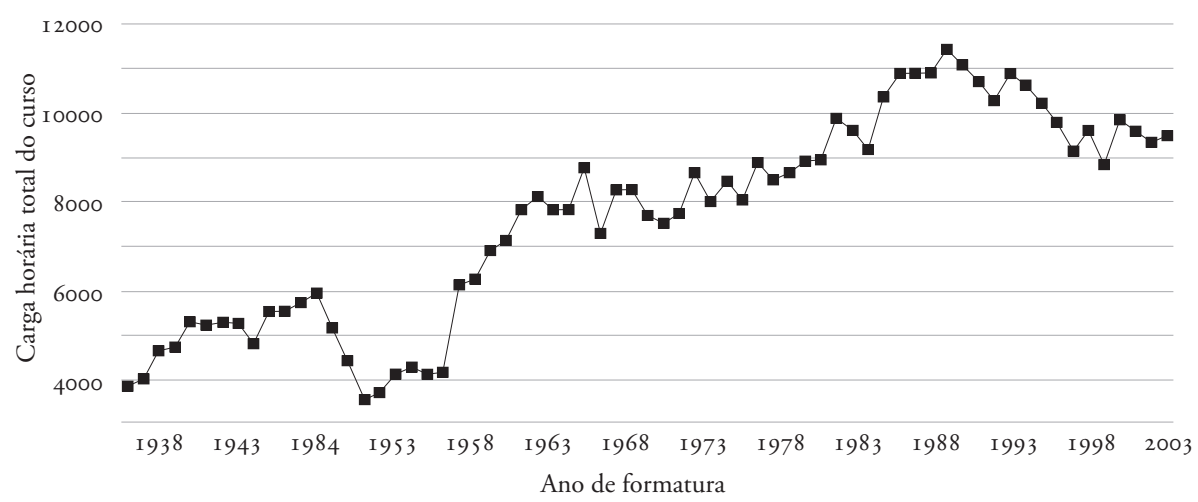

FIGURA 3. Registro histórico dos ingressantes do curso de Medicina na Unifesp relativo a (A) distribuição por gênero, (в) porcentagem de evasão e (С) carga horária total do curso. 


\section{REFERÊNCIAS BIBLIOGRÁFICAS}

Borges, D. R. \& Stella, R. C. R. i 999. "Avaliação do Ensino de Medicina na Universidade Federal de São Paulo”. Rev. Bras. Educ. Med., 23: I I-I 7.

Borges, D. R. 200 I. "Breve História do Departamento de Medicina da Universidade Federal de São Paulo". Folha Médica, I 20, pp. 69-I I 3.

Carvalho, O. I969. História da Escola Paulista de Medicina. Rio de Janeiro, Borsoi.

Conteúdo Programático do Curso de Medicina de I933 a 2005. Levantamento realizado por Marta Costa Penas da Pró-Reitoria de Graduação.

Escola Paulista de Medicina. I95 I. São Paulo, Ave Maria.

Escola Paulista de Medicina: 60 Anos de História. I993. São Paulo, Escola Paulista de Medicina.

Goldstein, J. L. \& Brown, M. S. I 997. “The Clinical Investigator: Bewitched and Bewildered - But Still Beloved”. J. Clin. Invest. 99, pp. 2803-28 I 2.

Prado, J. L. I966. "Sobre o Curso de Graduação, Mestrado e Doutoramento em Ciências Biomédicas da Escola Paulista de Medicina”, Ciência e Cultura, I 8, pp. 440-443.

Prado, J. L. I973. "Departamento: sua Conceituação e seu Papel Perante o Ensino e a Pesquisa”. Ciência e Cultura, 25, pp. 3 I I-3 I 5.

Ramos, J. A. I952. Problemas Fundamentais da Escola: Relatório Apresentado à Congregação da Escola Paulista de Medicina.

Thomas, L. I979. "Medical Lessons from History". The Medusa and the Snail. Penguin Books, pp. I58-175.

Valle, J. R. I977. A Escola Paulista de Medicina: Dados Comemorativos de seu 40 Aniversário (1933-1973) e Anotações Recentes. São Paulo, Empresa Gráfica da Revista dos Tribunais.

Watson, J. D. \& CRick, F. H. C. I953. "A Structure for Deoxyribose Nucleic Acid”. Nature, I7 I, pp. 737-738. 